\title{
Patients' attitudes and prior treatments in neuropathic pain: A pilot study
}

\author{
Ian Gilron MD MSc FRCPC ${ }^{1,2}$, Joan Bailey RN MEd ${ }^{1}$, Donald F Weaver MD PhD FRCPC ${ }^{3,4}$, \\ Robyn L Houlden MD FRCPC ${ }^{5}$
}

I Gilron, J Bailey, DF Weaver, RL Houlden. Patients' attitudes and prior treatments in neuropathic pain: A pilot study. Pain Res Manage 2002;7(4):199-203.

BACKGROUND: Ongoing research continues to expand the knowledge of neuropathic pain. It is vital that established treatments and valuable discoveries ultimately improve patient care. OBJECTIVES: Attitudes and prior treatments of patients being screened for neuropathic pain trials were evaluated to provide further understanding of the barriers to the management of neuropathic pain.

METHODS: A questionnaire was completed by patients with neuropathic pain who were either referred by local physicians or self referred in response to clinical trial advertisements from the authors' facility.

RESULTS: In total, 151 patients completed the questionnaire. Diagnoses included diabetic neuropathy $(55.6 \%)$, postherpetic neuralgia $(29.8 \%)$, idiopathic peripheral neuropathy (9.3\%) and others $(5.3 \%)$. The mean pain duration was 4.7 years, and the mean daily pain (on a score of 0 to 10 ) was 7.6. During questioning, $72.8 \%$ complained of inadequate pain control and $25.2 \%$ had never tried any antineuropathic analgesics (tricyclic antidepressants, opioids or anticonvulsants). New antineuropathic analgesics (eg, gabapentin) were being used by only $16.6 \%$. Opioids, tricyclic antidepressants and anticonvulsants had never been tried by $41.1 \%, 59.6 \%$ and $72.2 \%$, respectively. Fears of addiction and adverse effects were expressed by $31.8 \%$ and $48.3 \%$, respectively.

CONCLUSIONS: New, and even conventional, therapies are often not pursued, despite inadequate pain control. Several issues are discussed, including patient barriers to seeking pain manage- ment, patient and physician barriers to analgesic drug therapy, and appropriate use of and access to multidisciplinary pain centres. Failure to implement therapeutic advances in pain management not only hinders improvement in patient care, but also may render futile decades of research. Widespread professional, patient and public education, as well as continued interdisciplinary research on treatment barriers, is essential.

Key Words: Analgesic drug development; Barriers to treatment; Chronic nonmalignant pain; Diabetic neuropathy; Neuropathic pain; Pain measurement; Postherpetic neuralgia; Practice patterns; Randomized, controlled trials

\section{Rôle des attitudes et des traitements antérieurs dans la douleur neuropathique : Étude pilote}

HISTORIQUE : La recherche se poursuit pour approfondir nos connaissances sur la douleur neuropathique. Il est essentiel d'arriver un jour à des traitements établis et à des découvertes pour améliorer les soins aux patients.

OBJECTIFS : On a étudié les attitudes et les traitements antérieurs chez des patients qui subissent des examens pour douleurs neuropathiques afin de mieux comprendre les obstacles auxquels se bute le traitement de la douleur neuropathique.

MÉTHODES : Des patients souffrant de douleurs neuropathiques qui soit étaient adressés par un médecin de leur localité, soit se présen-

Suite à la page suivante

${ }^{1}$ Department of Anesthesiology, ${ }^{2}$ Department of Pharmacology and Toxicology, ${ }^{3}$ Department of Medicine, Division of Neurology, ${ }^{4}$ Department of Chemistry, and ${ }^{5}$ Department of Medicine, Division of Endocrinology, Queen's University, Kingston, Ontario

Correspondence: Dr Ian Gilron, Departments of Anesthesiology and Pharmacology and Toxicology, Queen's University,

76 Stuart Street, Kingston, Ontario K7L 2V7. Fax 613-548-1375, e-mail gilroni@post.queensu.ca

Received for publication July 11, 2002. Accepted July 23, 2002 
taient eux-mêmes en réponse à des publicités pour un essai clinique au sein de l'établissement des auteurs ont répondu à un questionnaire.

RÉSULTATS : En tout, 151 patients ont répondu au questionnaire. Les diagnostics incluaient neuropathie diabétique $(55,6 \%)$, névralgie postzostérienne (29,8\%), neuropathie périphérique idiopathique $(9,3 \%)$ et autres (5,3\%). La durée moyenne de la douleur était de 4,7 ans et la douleur quotidienne moyenne (sur une échelle de 0 à 10) se situait à 7,6. Dans le cadre du questionnaire, $72,8 \%$ des répondants se plaignaient d'un soulagement insuffisant et 25,2 \% n'avaient jamais essayé d'analgésiques antineuropathiques (antidépresseurs tricycliques, opiacés et anticonvulsivants). Les nouveaux analgésiques antineuropathiques (p. ex., gabapentine) n'étaient utilisés que chez 16,6 \% d'entre eux. Les opiacés, les antidépresseurs tricycliques et les anticonvulsivants n'avaient jamais été essayés par 41,1\%, 59,6\% et 72,2\%, respective- ment. La crainte de la dépendance et des réactions indésirables a été invoquée comme raison par $31,8 \%$ et $48,3 \%$ respectivement.

CONCLUSION : Souvent les traitements nouveaux et parfois même les traitements classiques ne sont pas utilisés et ce, même si la douleur n'est pas soulagée. Plusieurs problèmes sont abordés, y compris ceux qui empêchent les patients de consulter pour être soulagés, leurs réticences et celles des médecins face aux traitements analgésiques médicamenteux, l'utilisation appropriée de ces derniers et l'accès à des centres antidouleur pluridisciplinaires. En n'appliquant pas les progrès thérapeutiques réalisés dans le domaine de l'analgésie, non seulement on retarde les soins aux patients, mais on risque également de rendre inutiles des décennies de recherche. Il est essentiel de sensibiliser sans relâche et davantage les professionnels, les patients et le public et de procéder à des recherches interdisciplinaires sur les obstacles au traitement.
$\mathrm{O}^{2}$ ver the past 20 years, multidisciplinary efforts to advance the understanding of pain due to nerve injury or disease have demonstrated the merits of 'bench to bedside' research. Recognition of the complexities and treatment challenges posed by neuropathic pain has given laboratory investigators the impetus to develop clinically relevant animal models (1-3). By using such models, a wealth of information has been generated to support the therapeutic potential of several pharmacological agents, including novel opioids (4), adrenergic agonists (5), glutamate antagonists (6) and several new anticonvulsants (7). The development of preclinical human pain models (8) and the refinement of clinical research methodologies to study chronic pain (9) have facilitated the clinical evaluation of new analgesics. Furthermore, careful review of clinical trials data has put into context the clinical utility of the available drugs $(10,11)$. In this productive era, when suffering patients stand to reap the benefits of such research, it is crucial to ensure the timely application of promising new therapies as well as previously proven therapies. While comprehensive efforts have been made to understanding patient-related (12) and physician-related (13) barriers to the treatment of chronic cancer pain, attention in the area of nonmalignant pain has focused mostly on barriers to opioid use (14), and issues surrounding neuropathic pain and the introduction of new analgesics have, thus far, been neglected. Finally, it is vital to evaluate current treatment patterns with already established drugs because these patterns may provide additional insight into current treatment barriers. Therefore, we have undertaken a pilot research effort intended to identify barriers to, and guide strategies for, implementing established and new treatments in clinical practice.

The clinical application of new analgesic therapies is influenced by the investigators and institutions who develop them (in academia as well as industry), health care providers who prescribe them (both in primary and specialty practice), and patients who seek care and agree to try new treatments. As the ultimate recipients, patients are an ideal source of information and may provide preliminary insights on obstacles to the application of such new thera- pies. Thus, we have developed a pilot questionnaire for patients with neuropathic pain being considered for enrolment in analgesic clinical trials.

\section{SUBJECTS AND METHODS}

Ethics approval was obtained from the Research Ethics Board of Queen's University, Kingston, Ontario. Individual questionnaires were completed by patients with neuropathic pain who were either referred by physicians from Queen's University's Southeastern Ontario Health Sciences Centre catchment area or self referred in response to neuropathic pain clinical trial advertisements from the Queen's University Department of Anesthesiology. The questionnaire study period extended from March 1, 2001 to October 31,2001 . In conjunction with a detailed pain assessment, all questionnaires were completed over the telephone by the pain research nurse, who transcribed verbal responses onto individual forms (Appendix 1). In questions 8 and 9, 'new pain medicines' were defined as recently licensed drugs, drugs that the patient was not familiar with or drugs that the patient did not know were used for pain management (eg, antidepressants). Individual questionnaires were excluded from the results if the patient was suffering from a non-neuropathic pain syndrome or if the clinical diagnosis was uncertain or unknown. In cases in which the patient was unsure of the answer to a particular question (eg, diagnosis, previous drug dosage, etc), consent was obtained from that individual to consult with their primary physician and/or pain specialist to review the available medical records. Descriptive statistics were used to represent these data.

\section{RESULTS}

\section{Demographics and pain features}

Of the 195 patients who contacted the pain research nurse during the study period, nine did not complete the questionnaire, 35 were suffering from a non-neuropathic pain syndrome and 151 (age 64.9 \pm 12.4 years [mean \pm SD], 80 women and 71 men) completed the questionnaire (Table 1). Of all 151 neuropathic pain patients, 122 were self referred, and 29 were referred by a physician. Diagnoses included diabetic neuropathy $(55.6 \%)$, postherpetic neuralgia (29.8\%), idiopathic 
TABLE 1

Demographics and pain features of patients with neuropathic pain

\begin{tabular}{lcccc}
\hline Diagnosis & Sex (female to male) & $\begin{array}{c}\text { Age, years } \\
\text { (mean } \pm \text { SD) }\end{array}$ & $\begin{array}{c}\text { Pain duration, years } \\
\text { (mean } \pm \text { SD) }\end{array}$ & $\begin{array}{c}\text { Pain intensity } \\
\text { (mean } \pm \text { SD) }\end{array}$ \\
\hline Diabetic neuropathy $(\mathrm{n}=84)$ & $40: 44$ & $59.9 \pm 11.3$ & $4.9 \pm 4.0$ & $7.9 \pm 2.0$ \\
Postherpetic neuralgia $(\mathrm{n}=45)$ & $24: 21$ & $73.8 \pm 8.5$ & $2.5 \pm 2.5$ & $7.2 \pm 2.6$ \\
$\begin{array}{l}\text { Idiopathic peripheral neuropathy } \\
(\mathrm{n}=14)\end{array}$ & $12: 2$ & $67.8 \pm 13.1$ & $6.3 \pm 5.4$ & $7.1 \pm 1.8$ \\
Other neuropathic pain $(\mathrm{n}=8)$ & $4: 4$ & & & $7.5 \pm 3.4$ \\
\hline
\end{tabular}

*On a scale of 0 to 10

peripheral neuropathy $(9.3 \%)$ and other neuropathic pain $(5.3 \%$, lumbar radiculopathy $[\mathrm{n}=3]$, trigeminal neuropathy $[n=2]$, postchemotherapy neuropathy $[n=1]$, neuropathic cancer pain $[n=1]$ and occipital neuralgia $[n=1])$. The overall mean pain duration was $4.7 \pm 4.4$ years and the overall mean pain intensity (on a scale of 0 to 10 ) was $7.6 \pm 2.3$ (Table 1).

Pain treatment features and patient attitudes

Of all patients with neuropathic pain, $70.9 \%$ had never seen a pain specialist and $25.2 \%$ had never tried (either in the past or at the time of questioning) any antineuropathic analgesics (eg, tricyclic antidepressants, opioids or anticonvulsants). Opioids, tricyclic antidepressants and anticonvulsants had never been tried by $41.1 \%, 59.6 \%$ and $72.2 \%$ of patients, respectively. At the time of questioning, only $16.6 \%$ (15.2\% gabapentin, $1.3 \%$ topiramate) of respondents were using new drugs for which evidence of efficacy in neuropathic pain had emerged within the past five years $(15,16)$. At the time of questioning, $47.0 \%$ of respondents were taking nonprescription acetaminophen or nonsteroidal anti-inflammatory drugs, $38.4 \%$ were taking opioids (codeine 23.8\%, stronger opioids including morphine, oxycodone, hydromorphone and transdermal fentanyl 14.6\%), $21.9 \%$ were taking anticonvulsants (gabapentin $15.2 \%$, clonazepam $2.0 \%$, carbamazepine $2.0 \%$, valproic acid $1.3 \%$ and topiramate $1.3 \%$ ), $17.2 \%$ were taking tricyclic antidepressants and $9.3 \%$ were using topical or nonpharmacological therapies (including capsaicin and other topical creams or ointments, acupuncture, reflexology and magnet therapy). During questioning, $72.8 \%$ complained of inadequate pain control. Fear of addiction and adverse effects were expressed by $31.8 \%$ and $48.3 \%$, respectively.

\section{DISCUSSION}

Chronic pain causes patients profound dysfunction and suffering and has been estimated to cost North America at least $\$ 79$ billion per year in health care costs, disability compensation and litigation (17). Over the past 10 years, the United States National Institutes of Health alone has funded 1718 laboratory and clinical research project grants to study chronic pain, of which 335 were for studies of neuropathic pain (personal search, National Institutes of Health Computer Retrieval of Information on Scientific Projects Database [https://www-commons.cit.nih.gov/crisp/], November 2001). This number of neuropathic pain grants has risen dramatically from two grants in 1991 to 80 grants in 2001. Such increases in academic research, together with research and development in the pharmaceutical industry, are expected to yield new neuropathic pain treatments. It is crucial that barriers to implementing new cutting edge therapies be identified so that these hurdles can be overcome.

These data indicate that, in patients with poorly controlled neuropathic pain who pursue enrolment in analgesic trials, only $16.6 \%$ are trying any new drugs for which evidence of efficacy in neuropathic pain had emerged within the past five years. The infrequent use of nonpharmacological and alternative therapies indicates that these are not preferentially used over drug therapy in this group. Because our study methods are not based on exhaustive reviews of individual pharmacy records, it is possible that patient reporting was not entirely complete and that some previous therapies may have been missed. Nevertheless, the observation that $25.2 \%$ had never even tried any proven antineuropathic analgesics and that $70.9 \%$ were not referred to a pain specialist over an average of 4.7 years suggest that there are some critical barriers to pain management. We suggest that such barriers are not institution-specific, nor are they common to other chronic conditions but, rather, are unique to pain. For example, a comparison with epilepsy within our centre suggested that patients with epilepsy are much more likely than pain patients to be receiving drug treatment. Of the last 100 patients inquiring about clinical trials while seen at the Queen's University Epilepsy Clinic, $100 \%$ were taking an anticonvulsant, 38\% were already taking new anticonvulsants (eg, lamotrigine, topiramate or gabapentin) and $15 \%$ had a new anticonvulsant started by their family physician (D Weaver, unpublished data). Furthermore, a recent study suggested that, for cardiovascular, respiratory, gastrointestinal and psychiatric disorders, general practitioners tend to prescribe more new drugs than do consultants (18).

Previously identified pain management barriers $(12,13)$ such as patients' and physicians' denial of pain and fears of 
addiction may nonspecifically affect the implementation of new analgesics. However, analgesics, including new drugs, are most likely to be tried by physicians, either in primary or specialty practice, who have a thorough appreciation of both the potential and the limitations of available agents and would thus know when new alternatives are warranted. The majority of patients in this study were solely under the care of a primary physician. The observation that $70.9 \%$ of patients had not been referred to a specialist or multidisciplinary pain centre may be due to the primary physician's view that referral is unnecessary, the primary physician's view that other competing medical problems (eg, in diabetics or elderly postherpetic patients with multisystem disease) take priority over symptom management and/or insufficient community access. The clinical activities of several specialists from anesthesiology, neurology and physiatry at our centre make the latter less of an issue; however, insufficient access to pain clinics can often be a problem (19). Furthermore, it is important for community pain clinics to communicate with primary physicians to facilitate optimal use of these resources (20). Regardless of the reasons for under-referral, it is clear that family practitioners are positioned to play a pivotal role in chronic pain management (21), be it through clinical determination of individual treatment responses and/or through timely referral to a pain specialist. Comprehensive pain assessment, diagnosis and individual trial and titration of analgesic drugs (22) clearly demand a great deal of time and require a more complex physician-patient interaction than, for example, treating hypertension. In any case, if the importance of pain management is underestimated, neither primary pain management nor pain clinic referrals are likely to occur. Therefore, pain clinicians and researchers must promote the importance of pain management and participate in evidence-based physician education to ensure the appropriate application of new analgesic treatments. While new treatments are often proprietary pharmaceutical compounds promoted by their respective manufacturers, continuing medical education, as guided by industry, is often considered inadequate (23). Therefore, the authors propose that pain education be more academia-based, and supported by clinical trials data and widespread clinical experience from observational studies. Such information may be better disseminated by increasing the frequency and quality of presentations at primary care meetings and in primary care journals, and by further promoting pain education at the undergraduate and postgraduate levels (eg, family medicine residency programs).

As discussed earlier, effective pain management requires the patient to seek care and agree to try proposed treatments. In patients with diabetic neuropathy, symptoms tend to develop more slowly than peripheral nerve deterioration (24), and this insidious progression may make patients more likely to accept pain as part of their chronic illness. Also, this study group represents older patients (especially those with postherpetic neuralgia) who generally complain less about pain and have more concerns about addiction and side effects (12). In this study, 31.8\% expressed fear of addiction and $48.3 \%$ expressed fear of adverse effects when considering new analgesic treatments. While these are valid patient concerns, they are sometimes exaggerated (25), and patients are uninformed as to the profiles of specific agents, thus causing unnecessary avoidance of new therapies. Therefore, the clinical application of new analgesic treatments requires widespread public and patient education regarding the validity of chronic nonmalignant pain, the great potential for pain treatments to improve quality of life and a realistic perspective on the risk-benefit profiles of specific analgesic pharmacotherapies. Such information may be disseminated through national and regional patient associations (eg, American Chronic Pain Association), patient-oriented internet Web sites (eg, http://stoppain.org) and, most importantly, by health care providers (26).

While these preliminary data raise several issues regarding barriers to the implementation of analgesics, including new treatments, it should be noted that this population is somewhat skewed given that some neuropathic conditions are not represented (eg, central pain, phantom pain and post-traumatic neuropathic pain), that patient contact was made in the context of clinical trial enrolment and that most patients were self referred. Although these issues are of recognized importance in pain treatment studies (27), the observed degree of undertreatment of patients with such severe and prolonged pain, in a setting in which other chronic conditions are treated quite aggressively, cannot be overlooked and clearly emphasizes the need to understand and overcome obstacles to pain management.

The failure to appropriately implement established treatments as well as therapeutic advances in clinical pain management not only hinders improvement in patient care, but also may render futile decades of research. In conjunction with expanding knowledge, careful thought must be given to the clinical implementation of new therapeutics for neuropathic pain. This requires further investigation into barriers to treatment, as well as widespread professional, patient and public education. Future research efforts, involving the disciplines of psychology, nursing, pharmacology and medicine (both primary care and pain-related specialties) should focus on a number of wide-ranging questions, including: patient barriers to seeking health care for chronic nonmalignant pain, patient and physician barriers to analgesic therapy, and appropriate use of, and access to, multidisciplinary pain centres.

ACKNOWLEDGEMENTS: The authors thank Mr Allan Bell for his assistance with data management and Dr C Peter Watson for thoughtful comments made on previous versions of this manuscript. This work was supported by Canadian Institutes for Health Research Grant \#MCT-38149 and Queen's University Grant \#383-861. Donald Weaver's current affiliation is with the Departments of Medicine (Division of Neurology) and Chemistry, Dalhousie University, Halifax, Nova Scotia 


\section{APPENDIX 1 \\ Neuropathic pain treatment pilot questionnaire}

\section{Patient Information:}

Name:

Sex:

Date of birth:

Study \#:

2. What is the diagnosis your physician has given for your pain condition?

3. Have you seen a pain specialist, or a neurologist, for your pain condition?

4. For how long have you had this pain condition?

5. Based on the past month, how severe is your pain at its worst?

$\begin{array}{lllllllllll}0 & 1 & 2 & 3 & 4 & 5 & 6 & 7 & 8 & 9 & 10\end{array}$

no pain

worst pain imaginable

6. What treatments are you currently receiving for this pain condition? (include details about dose and dosing schedule).

7. Which treatments (that you are not taking now) have you previously tried for this pain problem? (include details about dose and dosing schedule).

8. Do you avoid trying new pain medicines because you are concerned about drug side effects?

9. Do you avoid trying new pain medicines because you are concerned about addiction?

10. Are your current pain treatments adequately controlling your pain?

\section{REFERENCES}

1. Bennett GJ, Xie YK. A peripheral mononeuropathy in rat that produces disorders of pain sensation like those seen in man. Pain 1988;33:87-107.

2. Kim SH, Chung JM. An experimental model for peripheral neuropathy produced by segmental spinal nerve ligation in the rat. Pain 1992;50:355-63.

3. Kalichman MW, Calcutt NA. Local anesthetic-induced conduction block and nerve fiber injury in streptozotocin-diabetic rats. Anesthesiology 1992;77:941-7.

4. Catheline G, Kayser V, Idanpaan-Heikkila JJ, Guilbaud G. The antinociceptive activity of kappa- but not delta-opioid receptor agonists is maintained in morphine-tolerant neuropathic rats. Eur J Pharmacol 1996;318:273-81

5. Puke MJ, Wiesenfeld-Hallin Z. The differential effects of morphine and the alpha 2 -adrenoceptor agonists clonidine and dexmedetomidine on the prevention and treatment of experimental neuropathic pain. Anesth Analg 1993;77:104-9.

6. Christensen D, Guilbaud G, Kayser V. Complete prevention but stimulus-dependent reversion of morphine tolerance by the glycine/NMDA receptor antagonist (+)-HA966 in neuropathic rats. Anesthesiology 2000;92:786-94

7. Hunter JC, Gogas KR, Hedley LR, et al. The effect of novel antiepileptic drugs in rat experimental models of acute and chronic pain. Eur J Pharmacol 1997;324:153-60.

8. Simone DA, Ngeow JY, Putterman GJ, LaMotte RH. Hyperalgesia to heat after intradermal injection of capsaicin. Brain Res 1987;418:201-3.

9. Max MB, Portenoy RK, Laska EM, eds. Advances in Pain Research and Therapy: The Design of Analgesic Clinical Trials, vol 18. New York: Raven Press, Ltd, 1991.

10. Collins SL, Moore RA, McQuay HJ, Wiffen P. Antidepressants and anticonvulsants for diabetic neuropathy and postherpetic neuralgia: A quantitative systematic review. J Pain Symptom Manage 2000;20:449-58.

11. Watson CP. The treatment of neuropathic pain: antidepressants and opioids. Clin J Pain 2000;16(Suppl):S49-55.

12. Ward SE, Goldberg N, Miller-McCauley V, et al. Patient-related barriers to management of cancer pain. Pain 1993;52:319-24.

13. Von Roenn JH, Cleeland CS, Gonin R, Hatfield AK, Pandya KJ. Physician attitudes and practice in cancer pain management. A survey from the Eastern Cooperative Oncology Group. Ann Intern Med 1993;119:121-6.
14. Turk DC, Brody MC, Okifuji EA. Physicians' attitudes and practices regarding the long-term prescribing of opioids for non-cancer pain. Pain 1994;59:201-8.

15. Rowbotham M, Harden N, Stacey B, Bernstein P, Magnus-Miller L. Gabapentin for the treatment of postherpetic neuralgia: A randomized controlled trial. JAMA 1998;280:1837-42.

16. Edwards KR, Glantz MJ, Button J, et al. Efficacy and safety of topiramate in the treatment of painful diabetic neuropathy: A double-blind, placebo controlled study. Neurology 2000;54(Suppl):A81. (Abst)

17. Bonica JJ. General considerations of chronic pain. In: JJ Bonica, ed. The Management of Pain, 2nd edn. London: Lea \& Febiger, 1990.

18. Jones MI, Greenfield SM, Bradley CP. Prescribing new drugs: Qualitative study of influences on consultants and general practitioners. BMJ 2001;323:1-7.

19. Davies HT, Crombie IK, Macrae WA. Waiting in pain. Delays between referral and consultation in outpatient pain clinics. Anaesthesia 1994:49:661-5.

20. Knab JH, Wallace MS, Wagner RL, Tsoukatos J, Weinger MB. The use of a computer-based decision support system facilitates primary care physicians' management of chronic pain. Anesth Analg 2001;93:712-20.

21. Smith BH, Hopton JL, Chambers WA. Chronic pain in primary care. Fam Pract 1999;16:475-82.

22. American Society of Anesthesiologists Task Force on Pain Management, Chronic Pain Section. Practice guidelines for chronic pain management. Anesthesiology 1997;86:995-1004.

23. Hayes TM, Allery LA, Harding KG, Owen PA. Continuing education for general practice and the role of the pharmaceutical industry. Br J Gen Pract 1990;40:510-2.

24. Boulton AJ, Armstrong WD, Scarpello JH, Ward JD. The natural history of painful diabetic neuropathy - a 4-year study. Postgrad Med J 1983;59:556-9.

25. Glajchen M. Chronic pain: Treatment barriers and strategies for clinical practice. J Am Board Fam Pract 2001;14:211-8.

26. Larue F, Fontaine A, Brasseur L. Evolution of the French public's knowledge and attitudes regarding postoperative pain, cancer pain, and their treatments: Two national surveys over a six-year period. Anesth Analg 1999:89:659-64.

27. Turk DC, Rudy TE. Neglected factors in chronic pain treatment outcome studies - referral patterns, failure to enter treatment, and attrition. Pain 1990;43:7-25. 


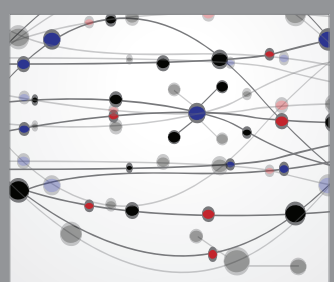

The Scientific World Journal
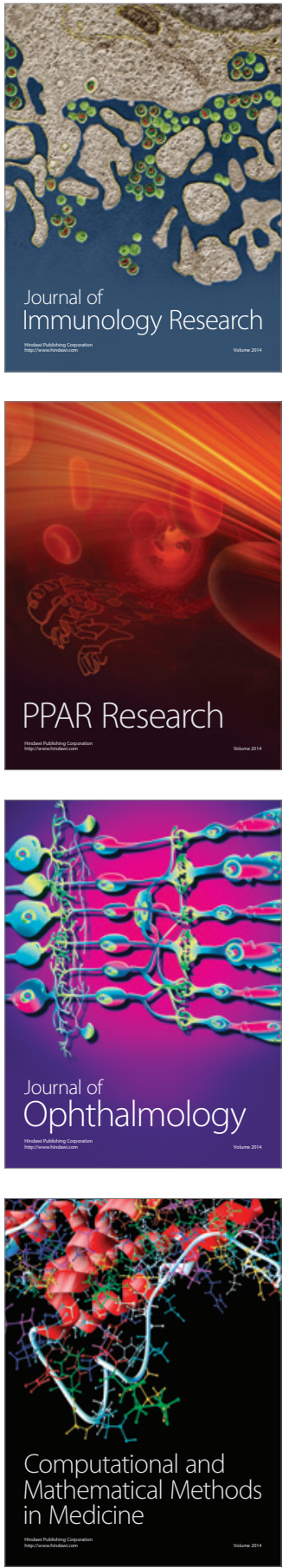

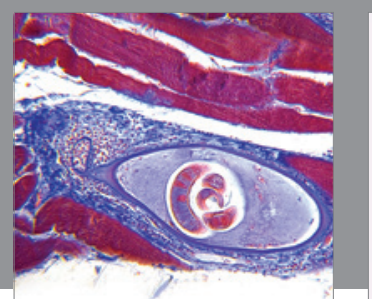

Gastroenterology Research and Practice

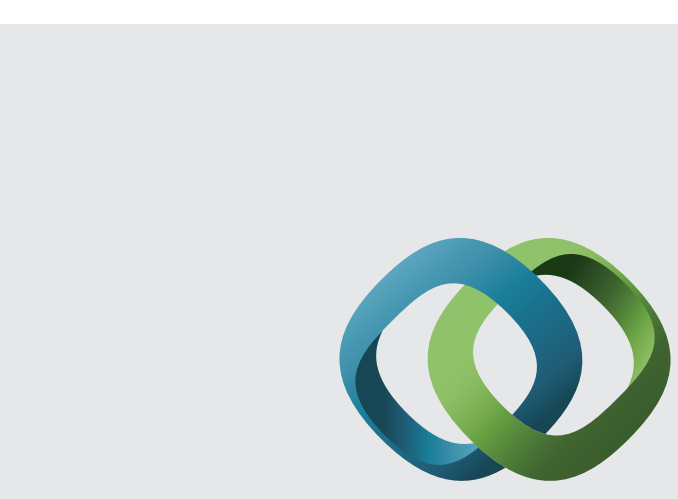

\section{Hindawi}

Submit your manuscripts at

http://www.hindawi.com
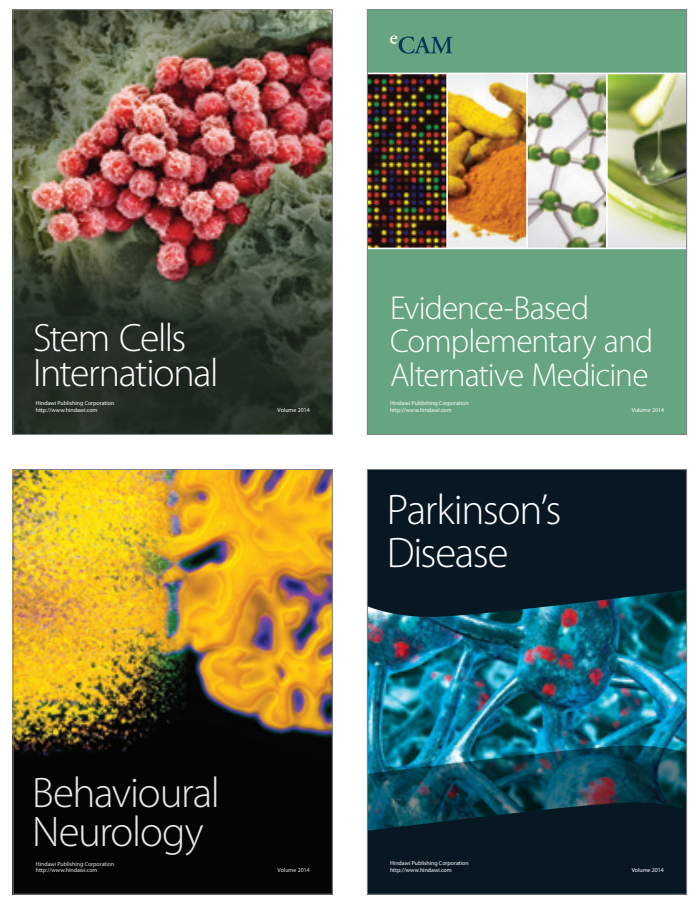
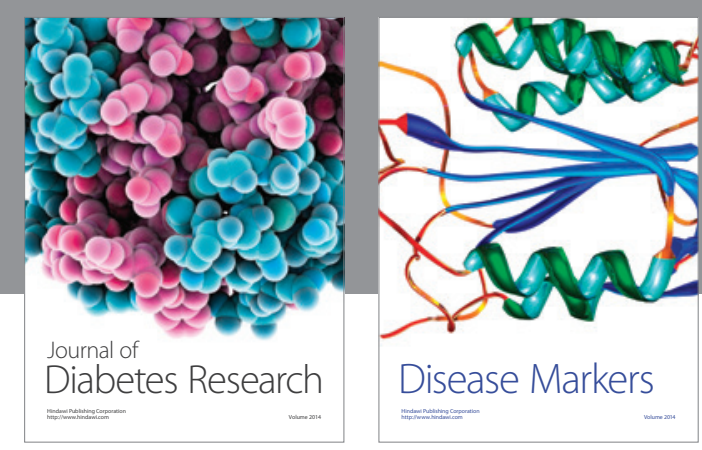

Disease Markers
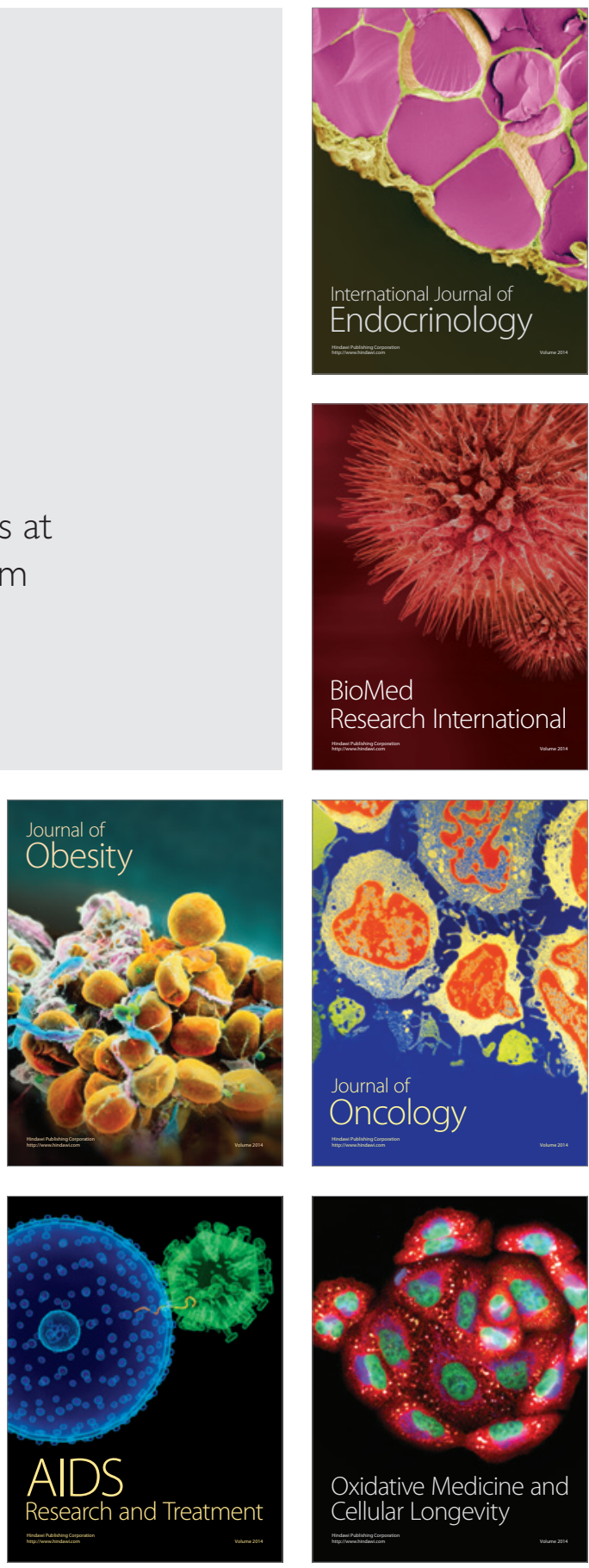